Bull. Mater. Sci., Vol. 17, No. 6, November 1994, pp. 1005-1014. (C) Printed in India.

\title{
Interfacial mechanisms controlling phase formation in sol-gel derived lead zirconate titanate thin films
}

\author{
S B MAJUMDER*, V N KULKARNI ${ }^{\dagger}, \mathrm{Y} N \mathrm{NOHAPATRA}^{*}$ and \\ D C AGRAWAL* \\ ${ }^{*}$ Materials Science Programme, ${ }^{\dagger}$ Department of Physics, Indian Institute of Technology, \\ Kanpur 208 106, India
}

\begin{abstract}
An RBS study has been carried out to study the relative extent of $\mathrm{Pb}$ diffusion in the substrate from PZT films. It is found that extensive diffusion of $\mathrm{Pb}$ occurs into the quartz substrate making the film severely deficient in $\mathbf{P b}$. No such diffusion occurs in the case of PZT films on sapphire and the concentration of $\mathrm{Pb}$ is near stoichiometric, except for a small loss due to volatilization. Excessive $\mathrm{Pb}$ deficiency, rather than any epitaxial effect, has earlier been proposed by us to be the crucial factor responsible for the existence of the pyrochlore phase in PZT thin films on substrates such as Si, glass, quartz etc. The present results confirm this. The effects of other process variables such as thickness and chemical composition ( $\mathrm{Zr} / \mathrm{Ti}$ ratio) of the film can also be understood in terms of the same phenomenon.
\end{abstract}

Keywords. PZT; phase formation; sol-gel; thin film.

\section{Introduction}

Ferroelectric materials display a variety of phenomena which include ferroelectricity (spontaneous electric polarization which can be reversed by an electric field), pyroelectricity (change in electric polarization due to a change in temperature), piezoelectricity (generation of electric charge by application of mechanical pressure or, conversely, production of mechanical strain by application of electric field), high dielectric constant and electro-optic behaviour. This makes these materials useful in a variety of applications (table 1). In the bulk form barium titanate $\left(\mathrm{BaTiO}_{3}\right)$ and lead zirconate titanate (PZT) have long been used as capacitors and piezoelectric elements respectively. In the thin film form also they have numerous present and potential applications. Some of these are shown for PZT in table 2. Thin films of lead zirconate titanate (PZT), chemically represented by $\mathrm{Pb}\left(\mathrm{Zr}_{x} \mathrm{Ti}_{1-x}\right) \mathrm{O}_{3}$, are currently being studied with increasing interest because of their potential use in piezoelectric, pyroelectric, electro-optic devices and non-volatile memory applications. Phase diagram for PZT is represented as a binary system between lead zirconate (PZ) and lead titanate (PT) (figure 1). In this system a morphotropic phase boundary (MPB) exists between the tetragonal and rhombohedral phases at $x=0.535$. The compositions near the MPB are of great technological importance because of pronounced maxima in certain properties.

For all applications of PZT, it is desirable to have the material in the ferroelectric perovskite phase, which is readily obtained in bulk and powder form. The as deposited films are usually amorphous and need to be annealed at $500-700^{\circ} \mathrm{C}$ to form the perovskite phase. However a pyrochlore phase which is cubic and is not 
Table 1. Ferroeluctric materials-phenomena and applications.

\begin{tabular}{ll}
\hline Phenomena & \multicolumn{1}{c}{ Applications } \\
\hline Dielectric & Capacitors, sensor, phase shifter \\
Fesroclectric & Non volatile memory \\
Pyroelectric & Pyrodetector \\
Piezoelectric & Acoustic transducer, sensor, SAW device, actuator \\
Electro-optic & Wave guide, optical memory, display modulator \\
\hline
\end{tabular}

Table 2. Thin film ferroelectric materials and application.

\begin{tabular}{lll}
\hline Material & Phenomena & Applications \\
\hline $\mathrm{Pb}\left(\mathrm{Zr}, \mathrm{Ti}_{3} \mathrm{O}_{3}\right.$ (PZT) & $\begin{array}{l}\text { Dielectric } \\
\text { Pyroelectric } \\
\text { Piezoelectric } \\
\text { Electro-optic }\end{array}$ & $\begin{array}{l}\text { Non volatile memory } \\
\text { Pyrodetector }\end{array}$ \\
& $\begin{array}{l}\text { SAW substrate } \\
\text { Wave guide device }\end{array}$ \\
& $\begin{array}{l}\text { Pyroelectric } \\
\text { Electro-optic }\end{array}$ & $\begin{array}{l}\text { Pyrodetector } \\
\text { Wave guide device } \\
\text { optical memory, SHG display }\end{array}$ \\
\hline
\end{tabular}

ferroelectric, first forms at low temperatures $\left(400-550^{\circ} \mathrm{C}\right)$ and often does not transform to the perovskite phase at higher temperatures. Thus the film after heat treatment has either the pyrochlore or the perovskite structure. Table 3 summarizes the data from literature. It is seen that factors such as nature of the substrate, thickness of the film, heat treatment conditions etc all influence the phase of the film. In a systematic work carried in our laboratory (Majumder et al 1994), films on sapphire, alumina, $\mathrm{NaCl}$ and $\mathrm{Pt}$ formed a perovskite phase while on quartz, glass and Si the pyrochlore phase was obtained. It was also found that the perovskite structure formed more easily if the film thickness was increased, or if $\mathrm{Zr} / \mathrm{Ti}$ ratio was decreased or if excess $\mathrm{Pb}$ was present.

The initial formation of the pyrochlore phase in thin PZT film has been attributed by us to the presence of a tensile stress in the film in the early stages of heat treatment (Majumder et al 1994). The strain energy considerations favour the formation of the pyrochlore phase which is $6.62 \%$ less dense than the perovskite phase. The subsequent pyrochlore to perovskite transformation depends as mentioned earlier on various factors which include thickness of the film, nature of substrates, composition, temperature etc. A crucial factor favouring the stabilization of the pyrochlore structure is a deficiency of $\mathrm{Pb}$ in the film (Tuttle et al 1990; Carim 1991; Krupanidhi et al 1992). This is because in the defect pyrochlore structure, represented by $\mathrm{A}_{2} \mathrm{~B}_{2} \mathrm{O}_{7-x}$, the $\mathrm{BO}_{6}$ octahedra are linked together and provide stability to the structure while $-\mathrm{A}-\mathrm{O}$ chains penetrate the $\mathrm{BO}_{6}$ octahedra but do not contribute much to the rigidity of the structure (Subramanian et al 1983). The pyrochlore thus can tolerate a large deficiency of $\mathrm{A}(\mathrm{Pb})$ and oxygen.

A loss of $\mathrm{Pb}$ usually occurs during the sintering of $\mathrm{Pb}$ based ceramics due to a high volatility of $\mathrm{PbO}$ at the sintering temperature $\left(1250^{\circ} \mathrm{C}\right.$ ) (Buckner and Wilcox 1972; Lucata et al 1985). In the case of thin films, $\mathrm{Pb}$ can additionally be lost 


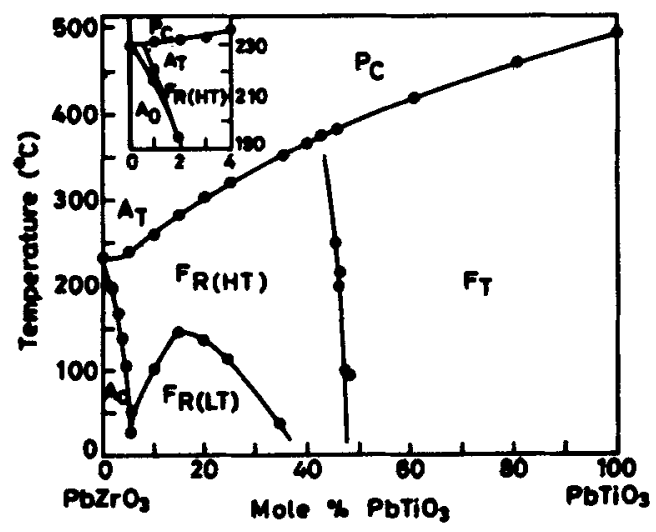

Figure 1. Phase diagram of lead zirconate-lead titanate solid solution.

Table 3. Summary of literature data on phases in PZT film.

\begin{tabular}{|c|c|c|c|c|c|}
\hline Composition & Treatment & Thickness & Substrate & Phase & Ref. \\
\hline $\mathrm{Pb}(\mathrm{Znu}$-5Tio-5 $) \mathrm{O}_{3}$ & $600^{\circ} \mathrm{C} / 1 / \mathrm{hr}$ & $\begin{array}{l}0.1 \mu \mathrm{m} \\
0.4 \mu \mathrm{m} \\
0.1 \mu \mathrm{m} \\
0.4 \mu \mathrm{m}\end{array}$ & $\begin{array}{l}7059 \text { glass } \\
7059 \text { glass } \\
\mathrm{Pt}, \mathrm{Al}_{2} \mathrm{O}_{3} \\
\mathrm{Pt}, \mathrm{Al}_{2} \mathrm{O}_{3}\end{array}$ & $\begin{array}{l}\text { Pyro } \\
\text { Pero } \\
\text { Pero } \\
\text { Pero }\end{array}$ & Takahashi et al (1992) \\
\hline PZT & $\begin{array}{l}15 \text { mins at } \\
\text { (i) } 450^{\circ} \mathrm{C} \\
\text { (ii) } 550^{\circ} \mathrm{C} \\
\text { (iii) } 600^{\circ} \mathrm{C} \\
\text { (iv) } 650^{\circ} \mathrm{C}\end{array}$ & $0.17 \mu \mathrm{m}$ & sapphire & $\begin{array}{l}\text { Amorphous } \\
\text { Pyro } \\
\text { Pyro + pero } \\
\text { Pero }\end{array}$ & Kwok et al (1992) \\
\hline PLZT & $\begin{array}{l}\text { (i) } 600^{\circ} \mathrm{C} / 30 \mathrm{~min} \\
\text { (ii) } 800^{\circ} \mathrm{C} / 30 \mathrm{~min} \\
\text { (iii) } 800^{\circ} \mathrm{C} / 30 \mathrm{~min}\end{array}$ & $\begin{array}{l}0.5 \mu \mathrm{m} \\
0.1 \mu \mathrm{m} \\
0.1 \mu \mathrm{m}\end{array}$ & $\begin{array}{l}\mathrm{Au}, \mathrm{Pt}, \mathrm{Al}_{2} \mathrm{O}_{3} \\
\text { Fused } \mathrm{SiO}_{2} \\
\text { Si (100) and } \\
\text { Si (111) }\end{array}$ & $\begin{array}{l}\text { Pero } \\
\text { No crystln } \\
\text { No crystln }\end{array}$ & $\begin{array}{l}\text { Seth and Schulze } \\
(1990)\end{array}$ \\
\hline
\end{tabular}

due to its diffusion into the substrate (Liples et al 1986; Seth and Schulze 1990). Such diffusion is likely to be greater in amorphous substrates as compared to inert crystalline substrate. It has been proposed (Majumder et al 1994) that the deficiency of $\mathrm{Pb}$ caused by such diffusion may in fact be responsible for the retention of the pyrochlore phase rather than any 'epitaxial' effect proposed in some reports (Takahashi et al 1990; Krupanidhi et al 1992).

To test this idea we have used Rutherford back scattering (RBS) in conjunction with X-ray diffraction (XRD) to investigate interfacial phenomena controlling phase formation in thin films of PZT of morphotropic composition on two typical substrates-fused quartz and sapphire. In this paper we present experimental evidence regarding the role of diffusion at the interface. 


\section{Experimental}

Thin films of approximately same thicknesses (70 to $390 \mathrm{~nm}$ ) were deposited on amorphous quartz and (1120) sapphire by a sol-gel technique described elsewhere (Majumder et al 1994). The composition of the sol was taken to be near the MPB region but with 5 mole\% excess $\mathrm{PbO}$ i.e. $\mathrm{Pb}_{1.05}\left(\mathrm{Zr}_{0.53} \mathbf{T i}_{0.47}\right) \mathrm{O}_{3}$. The sol was prepared using lead acetate, zirconium-n-propoxide, titanium-4-butoxide, isopropanol, water and ethylene glycol (to avoid cracking of the film). The relative amounts of various chemicals used in a typical sol are given in table 4 . The film was deposited by spin coating at $8000 \mathrm{rpm}$. The coated substrate was dried at $80^{\circ} \mathrm{C}$ for $20 \mathrm{~min}$. It was then heated at $5^{\circ} \mathrm{C} / \mathrm{min}$ to $400^{\circ} \mathrm{C}$ and held at that temperature for $30 \mathrm{~min}$ to drive off the organics. The temperature was then raised to $600^{\circ} \mathrm{C}$ and maintained for $6 \mathrm{~h}$ followed by furnace cooling. The thickness of the film was measured by a surface profilometer (Alpha Step-100, Tencor Instruments USA) and phases of the films were evaluated by X-ray diffractometer (Rich-Seifert Iso-Debyeflex 2002 , Germany) using $\mathrm{Cu} \mathrm{K} \alpha$ radiation with a monochromator. RBS spectra were obtained using $1.7 \mathrm{MeV} \mathrm{He}^{+}$ions from $2 \mathrm{MeV}$ Van-de-Graff accelerator facility. The back scattered particles were detected using a silicon surface barrier detector kept at a backscattering angle of $150^{\circ}$. All RBS spectra were analyzed using the versatile RUMP software package (Doolittle 1985, 1986).

\section{Results and discussion}

Figure 2 shows the $\mathrm{X}$-ray diffractograms for films of different thicknesses (a) on sapphire and (b) on fused quartz substrates. All the films on sapphire are in perovskite phase irrespective of thickness. We have checked it down to $450 \AA$ on sapphire substrate. On the other hand the first two relatively thinner films on quartz (IIA and IB) do not show any peak whereas sample IIC which is $3900 \AA$ thick yields a pyrochlore phase. We have also observed, in agreement with earlier reports, that films thicker than $1.5 \mu \mathrm{m}$ on quartz yield a perovskite phase. Note that the failure to obtain XRD peaks in samples IIA and IIB cannot be due to decreased volume of the material as seen by $\mathrm{X}$-ray since on sapphire the sample as thin as $450 \AA$ yields peaks corresponding to the perovskite phase under similar conditions.

Figure 3a shows RBS spectra-both experimental (dotted) and simulated (solid line)-for the films on sapphire substrate. The structures used for simulation are given in table 5. Simulated compositions of the film agree with nominal composition

Table 4. Typical cormposition of the coating sol used in the present study.

\begin{tabular}{ll}
\hline Material & Moles \\
\hline Lead acetate & 1.05 \\
Acetic acid & 6.60 \\
Zirconium-n-propoxide & 0.53 \\
Titanium-4-butoxide & 0.47 \\
Water & 0.52 \\
Ethylene glycol & 0.44 \\
\hline
\end{tabular}




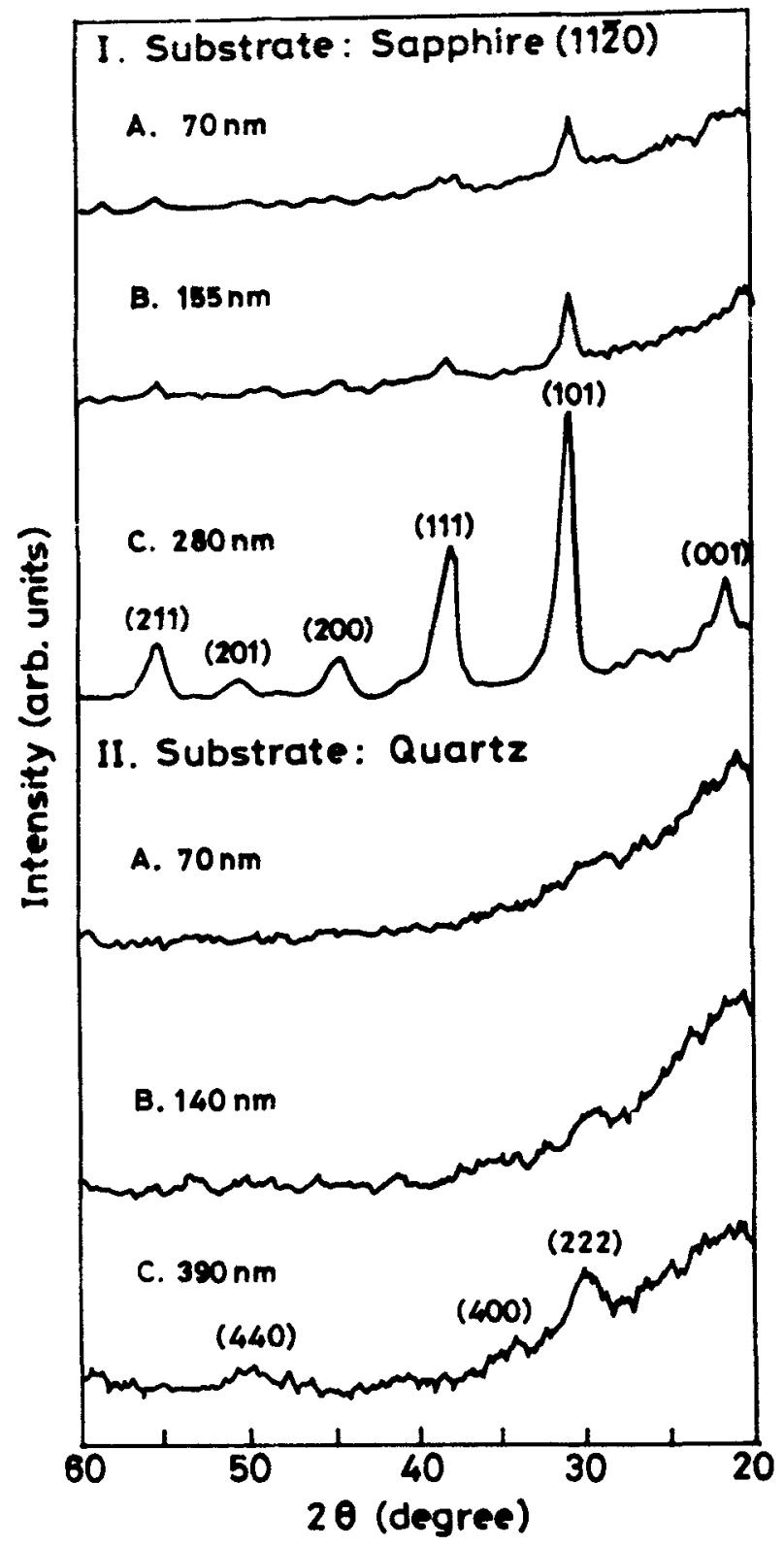

Figure 2. X-ray diffractograms of films on 1 : sapphire (1120) and Il : quartz, the perovskite phase is obtained on sapphire and the pyrochlore phase on quartz.

except for a small difference in $\mathrm{Pb}$ concentration. The thicknesses of simulated layers are also in agreement with profilometer measurements.

Figure 3b shows RBS spectra of the films on quartz substrate. In contrast with sapphire substrate, where the RBS spectra could be perfectly simulated using only one layer, it was found necessary to invoke multilayer structures of differing 
compositions to obtain simulated RBS spectra shown by solid lines in figure $3 \mathrm{~b}$ (i-iii). These structures are listed in table 6.

For thinner films the high energy peaks corresponding to $\mathrm{Pb}, \mathrm{Zr}$ and $\mathrm{Ti}$ are well separated and absolute concentrations of these heavy elements can easily be

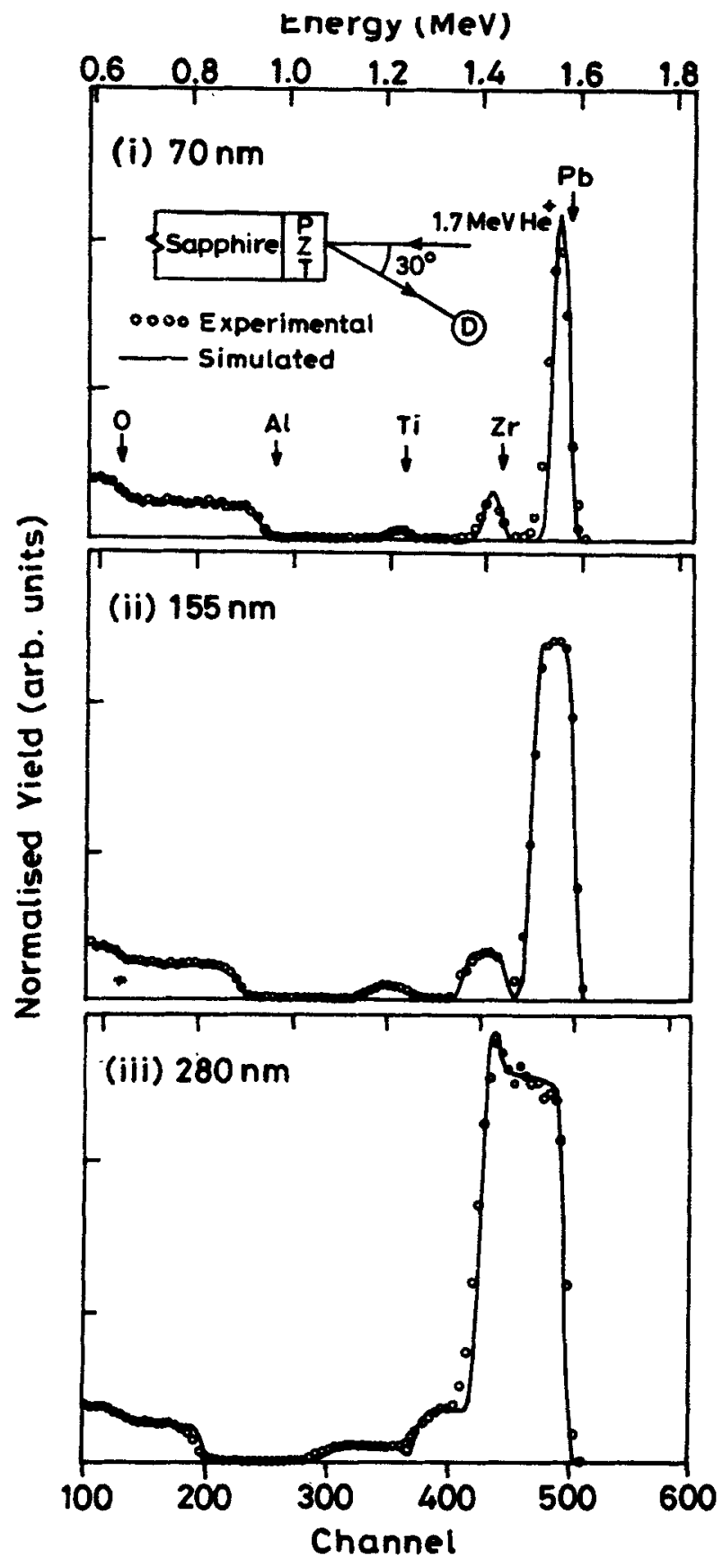

Figure 3a. For caption, sec 


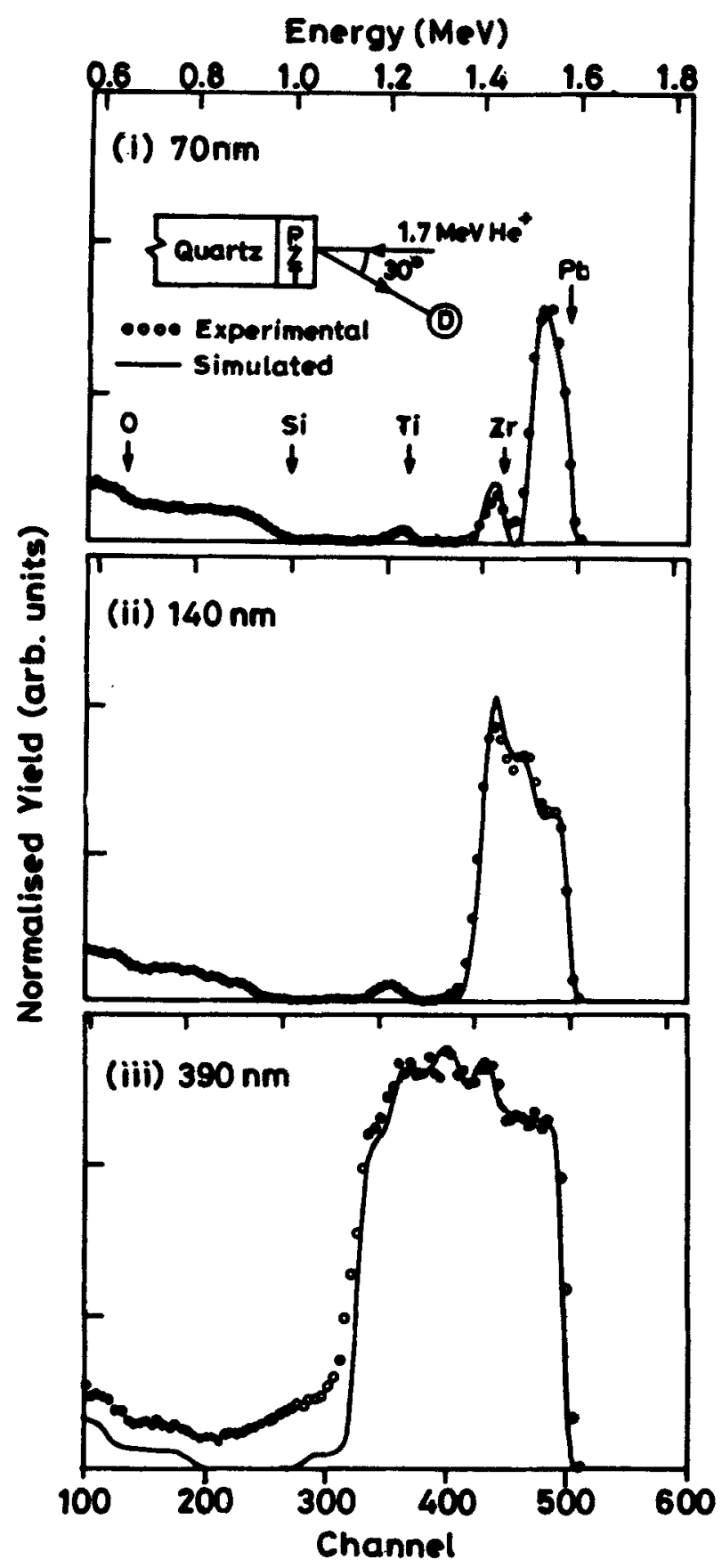

Figure 3. a-b. a. RBS spectra of PZT films of different thicknesses on sapphire (i) 70 $\mathrm{nm}$, (ii) $155 \mathrm{sm}$, (iii) $280 \mathrm{~nm}$; the arrows indicate the surface positions of the element shown and b. RBS spectra of PZT films of different thicknesses on fused quartz (i) $70 \mathrm{~nm}$, (ii) $140 \mathrm{~nm}$, (iii) $390 \mathrm{~nm}$; the arrows indicate the surface positions of the element shown. 
Table 5. Summary of X-ray and RBS results for PZT films on sapphire (11 $\overline{2})$.

\begin{tabular}{|c|c|c|c|c|c|}
\hline Sample no. & $\begin{array}{l}\text { Film thickness } \\
(\mathrm{nm})\end{array}$ & $X$-ray phase & $\begin{array}{l}\text { RBS simulation } \\
\text { structure }\end{array}$ & $\begin{array}{l}\text { Layer thickness } \\
(A)\end{array}$ & Layer \# \\
\hline \multirow[t]{2}{*}{ IA } & 70 & Perovskite & $\mathrm{Pb}_{0.92} \mathrm{Zro}_{53} \mathrm{Ti}_{-47} \mathrm{O}_{3}$ & 700 & 1 \\
\hline & & & $\mathrm{Al}_{2} \mathrm{O}_{3}$ & 15000 & 2 \\
\hline \multirow[t]{2}{*}{ IB } & 155 & Perovskite & $\mathrm{Pb0}-92 \mathrm{Zro}_{53} \mathrm{Ti0}-47 \mathrm{O}_{3}$ & 1550 & 1 \\
\hline & & & $\mathrm{Al}_{2} \mathrm{O}_{3}$ & 20000 & 2 \\
\hline \multirow[t]{2}{*}{$\mathrm{IC}$} & 280 & Perovskite & $\mathrm{Pb}_{1.0 \mathrm{Zru}} .53 \mathrm{Ti0.47 \textrm {O } _ { 3 }}$ & 3000 & 1 \\
\hline & & & $\mathrm{Al}_{2} \mathrm{O}_{3}$ & 20000 & 2 \\
\hline
\end{tabular}

Table 6. Summary of X-ray and RBS results for PZT films on fused quartz.

\begin{tabular}{|c|c|c|c|c|c|}
\hline Sample no. & $\begin{array}{l}\text { Film thickness } \\
(\mathrm{nm})\end{array}$ & X-ray phase & $\begin{array}{l}\text { RBS simulation } \\
\text { structure }\end{array}$ & $\begin{array}{l}\text { Layer thickness } \\
(\AA)\end{array}$ & Layer \# \\
\hline \multirow[t]{4}{*}{ IIA } & \multirow[t]{4}{*}{70} & \multirow[t]{4}{*}{ No pattern } & 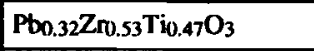 & 400 & 1 \\
\hline & & & $\mathrm{Pbo} .40 \mathrm{Zm} 0.53 \mathrm{Tiv} .{ }_{47} \mathrm{O}_{2.5 \mathrm{Si} 0.5}$ & 400 & 2 \\
\hline & & & $\mathrm{Pbo}_{.36} \mathrm{Si}_{1.0 \mathrm{O}_{2.25}}$ & 800 & 3 \\
\hline & & & $\mathrm{SiO}_{2}$ & 20000 & 4 \\
\hline \multirow[t]{4}{*}{ IIB } & \multirow[t]{4}{*}{140} & \multirow[t]{4}{*}{ No pattern } & $\mathrm{Pbo.38} \mathrm{Zn}_{0.53 \mathrm{~T}} \mathrm{in.47 \textrm {O } _ { 3 }}$ & 950 & 1 \\
\hline & & & $\mathrm{Pb}_{0.38} \mathrm{Zr}_{0.53} \mathrm{Ti}_{0.47} \mathrm{O}_{2.5 \mathrm{Si}} \mathrm{Si}$ & 400 & 2 \\
\hline & & & 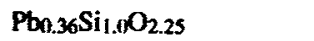 & 2200 & 3 \\
\hline & & & $\mathrm{SiO}_{2}$ & 20000 & 4 \\
\hline \multirow[t]{7}{*}{ IIC } & \multirow[t]{7}{*}{390} & \multirow[t]{7}{*}{ Pyrochlore } & $\mathrm{Pbo}_{.85 \mathrm{Zm} .53 \mathrm{Ti}} \mathrm{T}_{47} \mathrm{O}_{3}$ & 3000 & 1 \\
\hline & & & $\mathrm{Pbo.82} \mathrm{Zn}_{0.53 \mathrm{Ti}_{0.47} \mathrm{O}_{3}}$ & 200 & 2 \\
\hline & & & $\mathrm{Pb}_{0.71} \mathrm{Zr}_{0.53} \mathrm{Ti}_{0.47} \mathrm{O}_{2.5} \mathrm{Si}_{0.5}$ & 400 & 3 \\
\hline & & & $\mathrm{Pb}_{1.4 \mathrm{Si}_{2} \mathrm{O}_{6}}$ & 1000 & 4 \\
\hline & & & $\mathrm{Pb}_{1.2} \mathrm{Si}_{2} \mathrm{O}_{6}$ & 2000 & 5 \\
\hline & & & $\mathrm{Pb}_{1.0 \mathrm{Si}_{2} \mathrm{O}_{6}}$ & 1200 & 6 \\
\hline & & & $\mathrm{SiO}_{2}$ & 10000 & 7 \\
\hline
\end{tabular}

calculated. These are within $5 \%$ of those obtained from simulated spectra. No loss of $\mathrm{Zr}$ and $\mathrm{Ti}$ from the samples is observed. The discrepancy in total $\mathrm{Pb}$ concentration is less than $10 \%$ for films on quartz just as in the case of sapphire substrates. This $\mathrm{Pb}$ loss can be attributed to volatilization during heat treatment for both the 
cases. For the individual layers in case of quartz substrates, simulation can provide only ratios of various elements and hence it is important to fix at least one ratio from some other argument. The initial simulations showed that $\mathrm{Zr}$ and $\mathrm{Ti}$ concentrations do not change after heat treatment. The insignificant amount of tailing towards the low energy ends of $\mathrm{Zr}$ and $\mathrm{Ti}$ peaks can be attributed to depth undulation at the interface. Therefore $\mathrm{Zr} / \mathrm{Ti}$ ratio is fixed at the nominal composition (i.e. $0 \cdot 53 / 0.47$ ) and all other ratios are adjusted accordingly.

For the two relatively thinner samples on quartz, IIA and IIB, three layers had to be invoked in which top layer (layer 1) is only lead deficient while layer 2 , in addition, shows presence of $\mathrm{Si}$. The top two layers containing nominal $\mathrm{Zr} / \mathrm{Ti}$ ratio add up approximately to the thickness of the film obtained by profilometer measurements. This shows that the inter diffusion of $\mathrm{Pb}$ and $\mathrm{Si}$ has occurred across the original interface between PZT layer and quartz substrate leading most probably to the formation of a lead silicate compound (e.g. $\mathrm{PbSiO}_{3}$ or $\mathrm{PbSi}_{2} \mathrm{O}_{7}$ ). Layer 3 can then be viewed as arising out of lead silicate dispersed in quartz matrix. The presence of layer 2 in the structures of IIA and IIB is an indication that there is formation of lead silicate in PZT layer as well, spanning several hundreds of angstroms. In other words, lead silicate is dispersed on both sides of the original interface between PZT layer and the quartz substrate producing a structure consisting of three apparent layers corresponding to $\mathrm{Pb}$ deficient PZT (layer 1) mixture of PZT and lead silicate (layer 2) and lead silicate dispersed in quartz matrix (layer 3). The comparative thicknesses of layers 2 and 3 show that lead diffusion occurs deep into the substrate whereas the diffusion of Si into PZT layer is small.

The simulated structure for thicker sample IIC on fused quartz is similar except for the fact that the top PZT layer is subdivided into two layers (layers 1 and 2) and the intermediate layer into three layers (layer Nos $4,5,6$ ) reflecting $\mathrm{Pb}$ gradient in the whole structure as would be expected for a diffusing species. Layer No. 3 as earlier, is to be viewed as a part of PZT layer containing lead silicate phase. In this case the top three layers correspond approximately to the as-deposited film. Recall that no XRD peak was observed for cases of thinner films on quartz substrate (sainples IIA and IIB) suggesting that these films are amorphous. RBS results on these films show that the $\mathrm{Pb}$ deficiency in the top PZT layer is as high as $60 \%$. This suggests that these films are amorphous because $\mathrm{Pb}$ deficiency is too high for crystallization to occur. However in the thicker pyrochlore film (IIC) the overall $\mathrm{Pb}$ deficiency is $15 \%$ in the top PZT layer. It is reasonable to conclude that this level of $\mathrm{Pb}$ deficiency allows only a pyrochlore phase to form. When the film thickness is larger than $1.5 \mu \mathrm{m}$ the composition of the layer is nearly same as the nominal composition and gives rise to a perovskite phase-this has been checked by RBS results on such thick films. In contrast, in the case of sapphire substrates, $\mathrm{Pb}$ is neither consumed in any interfacial reaction nor it diffuses into the substrate. The marginal $\mathrm{Pb}$ loss in this case can be explained by losses due to evaporation from the surface. Therefore the perovskite phase forms in PZT layers on sapphire irrespective of thickness down to $450 \AA$. The existence of unusually long tail of $\mathrm{Pb}$ peak towards the low energy side is most probably due to some cracks that appear in the thicker films. This feature is absent in case of crack-free thinner films.

RBS results thus show that $\mathrm{Pb}$ diffuses readily from PZT film to a depth of several thousand angstroms into the quartz substrate during the annealing step. This 
results in a film highly depleted in $\mathrm{Pb}$. This deficiency in $\mathrm{Pb}$, rather than any substrate (epitaxial) effect is believed by us to be responsible for the retention of the amorphous or pyrochlore phase in the films on quartz. On sapphire where no such diffusion is found to occur, the perovskite phase forms readily.

The other observed effect relating to the phase formation can similarly be explained in terms of $\mathrm{Pb}$ deficiency in the film. Thus in thicker film, even on quartz, a perovskite phase is obtained because the top layer, which is the layer sampled in X-ray diffraction, does not develop $\mathrm{Pb}$ deficiency because of its large diffusion distance from the substrate. High $\mathrm{Ti}$ content (low $\mathrm{Zr} / \mathrm{Ti}$ ratio) also favours the perovskite formation because $\mathrm{Ti}$ binds $\mathrm{Pb}$ more effectively as revealed by much lower activity of $\mathrm{PbO}$ in $\mathrm{PbTiO}_{3}$ than in $\mathrm{PbZrO}_{3}$ (Klee et al 1992), the loss of $\mathrm{Pb}$ thereby is less in composition with lower $\mathrm{Zr} / \mathrm{Ti}$ ratio.

\section{Summary}

The difficulty in the formation of the perovskite phase in PZT films under certain experimental conditions is directly related to the extent of $\mathrm{Pb}$ loss from the film. If the $\mathrm{Pb}$ loss is not significant, then the perovskite structure forms easily. This is the case, for example, for thin films on substrates such as sapphire, platinum etc where the only $\mathrm{Pb}$ loss mechanisms is the volatilization of $\mathrm{PbO}$ during annealing. When $\mathrm{Pb}$ is also lost due to diffusion into the substrate or due to reaction with the substrate then the film may become heavily deficient in $\mathrm{Pb}$ and will not transform to the perovskite structure. Such diffusion is found to be substantial for amorphous substrates such as quartz.

For using the ferroelectric PZT film in non-volatile memory application, it is desirable to integrate the film with $\mathrm{Si}$ semiconductor technology. In view of the high reactivity of $\mathrm{Pb}$ with $\mathrm{Si}$, and consequent difficulty in the formation of perovskite phase, it would be necessary to develop suitable diffusion barrier layers between PZT film and Si substrate. Development of such barrier layer is one of the most important issues in utilizing PZT film in memory application.

\section{References}

Buckner D A and Wilcox P D 1972 Am. Ceram. Soc. Bull. 51218

Carim A H 1991 J. Am. Ceram. Soc. 741455

Doolittle L R 1985 Nucl. Inst. Method B9 334

Doolittle L R 1986 Nucl. Inst. Method B15 227

Klee M, Eusemann E, Waser R, Brand W and Hal Van H 1992 J. Appl. Phys. 721566

Krupanidhi S B, Hu H and Kumar V 1992 J. Appl. Phys. 71376

Kwok C K and Desu S B 1992 Appl. Phys. Lett. 601992

Liples R A, Ives N A and Leung M S 1986 in Science of ceramic processing (ed) L L Hench and D R Ulrich (New York: Wiley) p. 320

Lucata P G, Constantinescu FI and Barb D $1985 \mathrm{~J}$. Am. Ceram. Soc. 64553

Majumder S B, Agrawal D C, Mohapatra Y N and Kulkarni V N 1994 Ferroelectrics (communicated) Seth V A and Schulze W A 1990 Ferroelectrics 112283

Subramanian M A, Aravamudan G and Subbarao G V 1983 Prog. Solid State Chem. 1555

Takahashi Y, Matsuoka T, Yamaguchi K, Matsuki M and Kobayashi K $1990 \mathrm{~J}$. Mater. Sci. 253960

Tuttle B A, Schwartz R W, Doughty D H and Voigt J A 1990 Mater. Res. Soc. Symp. Proc. 200159 